\title{
Home as Workplace: A Qualitative Case Study of Online Faculty Using Photovoice
}

\author{
Lee Stadtlander \\ Walden University \\ Amy Sickel \\ Walden University \\ Lori La Civita \\ Walden University \\ Martha Giles \\ Walden University
}

The present study examined how online faculty members structure their workspace in their homes and how their work situation affects their home environment. The case study's goal, guided by an extension of Vischer's user-centered model of the work environment, was to address this research gap through interviews and using photovoice, a technique in which participants take photos and are interviewed about them. Eighteen faculty members from a large online university were recruited through ads in the faculty newsletter. The inclusion criterion was that the individual must only work online. Interested individuals completed an email interview and emailed a photo of the area they considered work. Each participant was interviewed about his or her responses and photos for 15-20 min on the telephone. Many participants consciously separated their home and workplace through either utilizing a separate room/area or maintaining a work schedule that separated work and home through time management. However, the technology required for conducting their work (e.g., computer, printer, etc.) also played a strong role in the choice of maintaining a separate workspace; especially for full-time faculty. The use of photovoice offered insights into how participants perceived and thought about their workspace. Of concern, for some faculty members was the surroundings within their defined workspace; having their books available and a beautiful view from their window were mentioned.

Keywords: online faculty, distance faculty, remote faculty, telecommuting, university, photovoice, work environment

\section{Introduction}

Online (also known as distance or remote) learning has become a ubiquitous entity: In 2014, 2.85 million students took all their courses at a distance and 2.97 million took some, but not all, courses at a distance (Allen \& Seaman, 2016). The essential characteristic of distance learning programs is that students and instructors are geographically dispersed (Murphy, Levant, Hall, \& Glueckauf, 2007). Students and instructors may be not only anywhere in the United States, but also throughout the world. The number of faculty teaching online is uncertain, however, it is known that many are part-time employees (Allen \& Seaman, 2016), and virtually all work from their home. 
There has recently been research examining issues in the online education workplace, some examples include stress and burnout in online faculty (Kennedy et al., 2015) and cyber-bullying and incivility online (Clark, Werth, \& Ahten, 2012; Eskey \& Eskey, 2014). Tustin (2014) examined perceptions of online versus brick-and-mortar faculty as to their attitudes toward online teaching.

There is very little research on how online faculty work within their homes. Oliver (2009) conducted the only previous study on the online faculty home/work environment through a qualitative study of 26 community college faculty who worked both online and in person. However, Oliver was primarily interested in the dynamics of teaching online and how the faculty members adjust their teaching style to the online environment. Oliver did not ask about where or when faculty did their work. Little is known about how faculty members who only work virtually structure their home environment and how their work situation affects their home; the present study addresses this gap in the literature.

\section{Telecommuting and the Virtual Work Environment}

There is a related literature on telecommuters: individuals who work virtually for an outside organization from within their own homes. Traditionally, telecommuting has been defined as a work mode that may also encompass working in multiple satellite offices or other remote locations away from home. Telecommuters typically allocate their work time between an office and home (Golden, Veiga, \& Simsek, 2006; Madsen, 2003; Nilles, 1994; Nuwer, 2016; Pratt, 1999). However, recent definitions (e.g., in Ross, 2016) have acknowledged that telecommuters are frequently working in remote locations and often do not have a centralized work location owned and operated by their companies; thus, workers' connections to an organization, managers, and peers vary greatly. The Bureau of Labor Statistics (2016) reported that in 2015, 24.1\% of workers did some or all their work at home.

Some studies have suggested that telecommuting provides individuals with the opportunity to cope with the competing demands of work and family domains, thereby reducing conflict (e.g., Rau \& Hyland, 2002; Stephens \& Szajna, 1998). Others have countered that it gives rise to greater conflict because of additional family demands resulting from greater proximity and accessibility (e.g., Igbaria \& Guimaraes, 1999; Kurland \& Bailey, 1999) or that it has no effect on work-life balance (Hill, Miller, Weiner, \& Colihan, 1998; Nuwer, 2016). Golden et al. (2006) reported that job autonomy, scheduling flexibility, and household size moderated telecommuting's impact on family and work conflict.

In many ways, online faculty members exemplify the new virtual teleworker. Online faculty may work at multiple colleges and universities, which may or may not have a centralized campus. Their interactions with supervisors vary a great deal between universities, and faculty may feel unconnected to their employer (Stadtlander, Sickel, \& Giles, 2014). Yet, little is known about how faculty members who only work online structure their workspace in their homes and how their work situation affects their home environment.

\section{A Virtual Workplace Model}

Vischer $(2007,2008)$ analyzed the workplace as a physical, functional, and psychological entity in order to identify features related to the comfort and fit between a workplace and an employee. Vischer conceptualized workers as seeking a level of comfort and manipulating their environment to achieve it. Vischer's model of environmental comfort encompasses three hierarchical categories: the physical, functional, and psychological. Physical comfort relates to basic human needs (i.e., safety, hygiene, and accessibility). Functional comfort is defined in terms of support for users' performance in work-related tasks and activities. Psychological comfort is related to feelings of belonging, ownership, and control over the workspace. 
Hyrkkänen, Nenonen, and Kojo (2012) extended Vischer's $(2007,2008)$ user-centered model to accommodate the virtual worker. Hyrkkänen et al. (2012) proposed that it is important for the virtual worker to develop psychosocial comfort in their work environment. The authors related this notion to the mechanics of computer and virtual tool (e.g., smartphone) use; however, it seems logical that the model could include the home work environment and how online faculty members manipulate that environment to accommodate their needs. The purpose of the present study is to extend the previous work in this area and examine how faculty who teach only online control their workspace at home and how working at home has affected their feelings about their work and home environment. The present study addressed these issues through interviews and the use of photovoice.

\section{Photovoice}

Photovoice is a form of participatory action research. The method is a valuable way to uncover participants' views of their worlds and the challenges they face (Julien, Given, \& Opryshko, 2013). In photovoice, participants are asked to photograph what is salient in their everyday worlds, giving attention to a phenomenon of interest, in the present case, their online work area. The resulting photographs are used as prompts for discussions about the meanings and significances that the participants attach to the documented activities or objects.

In the current descriptive case study, the "case" refers to the process of online faculty working within their home; the study's purpose is to understand how faculty who teach only online control their workspace at home and how working at home has affected their feelings about their work and home environment. Understanding how virtual workers separate home from work provides employers with an opportunity to help new employees better care for themselves, resulting in potentially higher job satisfaction and productivity.

Four research questions guided the study.

Research Question 1. Do online faculty members separate home from workplace?

Research Question 2. How has working online affected feelings of home for online faculty and their family?

Research Question 3. How does their home environment affect their online work?

Research Question 4. How do online faculty members visualize their home workplace?

\section{Method}

Following approval from Walden University's Institutional Review Board, ads were placed in the faculty monthly newsletter for 6 months (June through November 2015). The inclusion criterion was that the individual must only work online with no brick-and-mortar office. Interested individuals were sent the consent form and an email interview (see the Appendix), participants were also asked to email a digital photo of the area they considered work. No images of people or identifiable documents (e.g., on computer screens) were to be included. Each participant gave consent for the use of their photo in publications by the researchers. Each participant was interviewed about his or her responses to the email interview and photos for 15-20 min on the telephone by a researcher (see interview questions in the Appendix).

A total of 26 faculty members offered to participate in the qualitative case study; however, only 18 faculty completed the full interview process. As shown in Table 1, of the 18 participants, 13 were females (five were full time) and five were males (three full time). Note that while "part-time" faculty members were part time for the university setting of the study, they may work online for multiple colleges or universities. 
Table 1. Demographics of Participants

\begin{tabular}{|c|c|c|c|c|c|c|c|}
\hline $\begin{array}{l}\text { Subject } \\
\#\end{array}$ & Age & Gender & Race & Work Status & $\begin{array}{c}\text { Children at } \\
\text { Home }\end{array}$ & $\begin{array}{c}\text { Years at } \\
\text { Institution }\end{array}$ & $\begin{array}{c}\text { Years } \\
\text { Teaching }\end{array}$ \\
\hline 1 & 65 & Male & Caucasian & Full time & No & 3 & 10 \\
\hline 2 & 54 & Female & Caucasian & Full time & No & 2 & 15 \\
\hline 3 & 56 & Female & Caucasian & Part time & No & 1 & $\begin{array}{c}\text { Full-time } \\
\text { administration }\end{array}$ \\
\hline 4 & 42 & Female & Caucasian & Full time & No & 6 & 15 \\
\hline 5 & 71 & Male & Caucasian & Full time & No & 3 & 44 \\
\hline 6 & 68 & Female & Other & Part time & No & 10 & 43 \\
\hline 7 & 68 & Male & Caucasian & Part time & No & 3 & 35 \\
\hline 8 & 65 & Female & Caucasian & Full time & No & 6 & 13 \\
\hline 9 & 47 & Male & Caucasian & Full time & No & 14 & 14 \\
\hline 10 & 30 & Female & Caucasian & Part time & No & 3 & 5 \\
\hline 11 & 43 & Female & Caucasian & Part time & Yes & 2 & 20 \\
\hline 12 & 64 & Female & $\begin{array}{c}\text { Native } \\
\text { American }\end{array}$ & Part time & No & 2 & 10 \\
\hline 13 & 36 & Female & Caucasian & Part time & No & 1 & 15 \\
\hline 14 & 48 & Female & Caucasian & Part time & No & 3 & 16 \\
\hline 15 & 37 & Female & Caucasian & Full time & Yes & 5 & 12 \\
\hline 16 & 39 & Female & Caucasian & Full time & Yes & 5 & 15 \\
\hline 17 & 64 & Female & Caucasian & Part time & No & 8 & 30 \\
\hline 18 & 49 & Male & Caucasian & Part time & Yes & 5 & 15 \\
\hline
\end{tabular}

\section{Results}

There were four research questions as the basis for the present qualitative case study. The first research question asked if online faculty members separate their home from their workplace. Two interview questions examined this issue: (a) "Tell me how you structure your environment to be able to work online at home." and (b) "Do you feel that you separate your work environment from your home environment? If so, how do you do that?"

The most common theme ( $n=12 ; 7$ or $87.5 \%$ were full time) related to structuring the home environment for work was to have a room dedicated as an office or study. For example, "My office is separate from the rest of the house (we bought it for that reason) and I typically sit at my office desk most of the day, even though I can take my laptop elsewhere" (Subject 15, female, age 37, full time). Three indicated having a desk, but did not use the term office or study. Three worked in other areas of the house, such as kitchen or living room.

Many faculty members ( $n=12,66.7 \%$ ) mentioned a theme related to the importance of the technology aspect of their work, which required an office. "I have two large high-definition screens that I work primarily from. One is attached to a (university-provided) laptop, the other to a private PC for back-up us" (Subject 2, female, age 54, full time). "I work with three screens, and so doc editing and professional writing is most often done in my study. I have a good tablet for reading student drafts just about anywhere-downstairs on the couch, in the bathtub, or outside" (Subject 6, female, age 68, part time).

A third theme was mentioned by five faculty members (three part time) that structuring their work hours helped them to separate home from work life. "I prefer to work mostly during the day during the week. I do try to log in once on the weekend as well and check email" (Subject 2, female, age 54, full time). "My hours are comparable to a regular work day (8 a.m.-5 p.m.) and I schedule my days accordingly, although I know there is some flexibility" (Subject 15, female, age 37, full time). 
Interestingly, one male and two females indicated that they had no separation between work and home.

I am not able to separate work from home, because they are the same. I work off and on all day from 8:00 a.m. until 10:00 p.m. I help my 88-year-old aunt with shopping, medications, and provider visits in the afternoon. I do separate work from caring for her. I love the flexibility of online work, because if I have a morning commitment, then I just rearrange my schedule. I begin my day with running and prayer, which helps me focus. I do not see online work the same as office work, and there is no need for me to separate home from helping fellow nurses. Nursing is my life. (Subject 3, female, age 56, part time)

I find that I do not do a good job at all separating my work and my personal time. However, I prefer it this way, as I am able to spread my time across more hours, which allows me to do things I want to do during the day such as the gym or Starbucks. (Subject 9, male, age 47, full time)

While it would be nice to have an office or something similar, this is not an option for me right now. No, my home environment is my work environment. I'm not sure that I would even work better in an office as I like to move around a bit. (Subject 13, female, age 36, full time)

A commonly reported method of structuring their environment was not answering the telephone $(n=$ 7; [5 part time]). "I turn off my phones, emails, and won't answer the door. Again, because of my tunnel-vision, those methods work great for me" (Subject 15, female, age 37, full time).

My major reduction of interruptions is that I do not answer the phone almost ever when I am in the house unless it is my partner or family. Otherwise, all calls go to voicemail. I tell the students right from the start that they can reach me almost anytime by email, but I don't take cold calls because I want to be prepared when I speak with them. I have them trained. (Subject 6, female, age 68, part time)

Many faculty members in the present study have considered the issue of separating home and work and have developed methods to maintain the separation. Full-time faculty were more likely to report having a separate room that they use as an office, while part-time faculty more often reported structuring their work time and not answering the telephone while at work. A number of participants mentioned that while they have a main work location, such as an office, they may work in other locations on a tablet or laptop around their home or in a coffee shop as a change of venue.

The second research question asked if working online affected feelings of home for online faculty and their family. One interview question addressed this: "Do you feel that the ambiance or feeling about your home has changed for you or your family due to working at home? Describe the changes that you have seen."

For the first theme, the majority of respondents $(n=16,88.9 \%)$ stated that the ambiance of home had not changed. "There have been no changes. We have always had academic work to do from home, even before the internet, so not much has really changed" (Subject 7, male, age 68, part time). "I do not feel the ambiance 'about our home' has changed. My office/work is isolated from the rest of the house and I try to keep it like that" (Subject 15, female, age 37, part time).

Two faculty members indicated feeling that working online does affect the ambiance of home. "Definitely, working from home changes that ambiance. In some ways, when you work from home, you are always working. I have tried to fix that but nevertheless, it is true" (Subject 14, female, age 48, part time). "Yes, I would say it has definitely changed the feeling of 'homeness.' Even though 
there is a physical separation between 'home' and 'work' setting, the 'being at home' and 'being at work' perceptions have definitely blended” (Subject 18, male, age 49, part time).

The third research question asked how their home environment affects their online work. One interview question related to this research question: "Are there any other benefits/problems with working at home that you would like to share?" The responses can be grouped into positive and negative aspects. On the positive side, $13(72 \%)$ faculty members mentioned that working at home provided flexibility. "It's easy to arrange my schedule to accommodate appointments, phone calls, etc." (Subject 10, female, age 30, part time). "The advantages are the flexibility. As long as I get the work done, I can basically do it any time. I really try to get it done during the day, but I'm not always successful" (Subject 3, female, age 49, full time). Other positive aspects to their work included "it is easier to control for potential interruptions" (Subject 7, male, age 68, part time) and "I'm less stressed in the morning about getting to work" (Subject 4, female, age 42, full time).

However, there were negatives to the home work environment, for example, "Working from home can also be lonely. I miss working with my colleagues in a face-to-face setting" (Subject 10, female, age 30, part time). "I miss actually seeing and talking to colleagues, but when I think back to my positions in campus-based universities, I mainly miss the social life" (Subject 10, female, age 68, part time). Another reported negative was people assuming that because the individuals worked at home, they were open to interruptions: "Some people think working from home means I don't work. However, my friends and family who know me know better. They have learned to respect my time... although at first that required my reminders to them" (Subject 18, male, age 49, part time). "The interruptions are hard for me to manage, which is why I leave difficult tasks for the 9-to-midnight 'shift.' I often feel like I work third shift" (Subject 12, age 64, part time).

The fourth research question was based on the technique of photovoice: "How do online faculty visualize their home workplace?" Participants were asked to submit digital photos of the location that felt like work to them, and subsequently interviewed about the photos. In descriptions of their workspace, the most common theme that 12 faculty mentioned was the importance of technology in choosing and setting up their work area. For example, "There is room for my computer, printer, and extra screen" (Subject 3, female, age 56, part time). Setting up an area/office exclusively for their online work was common, photos shown in Figures 1 and 2 illustrate some examples.

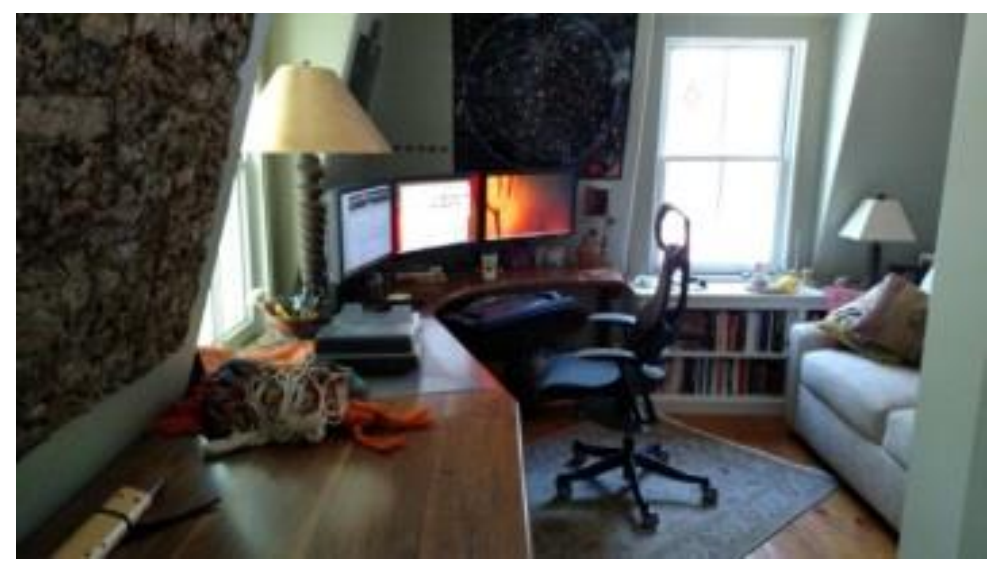

Figure 1. "I Have Three Screens-Can Have Several Documents/Sites Open" (Subject 6, Female, Age 68, Part Time) 


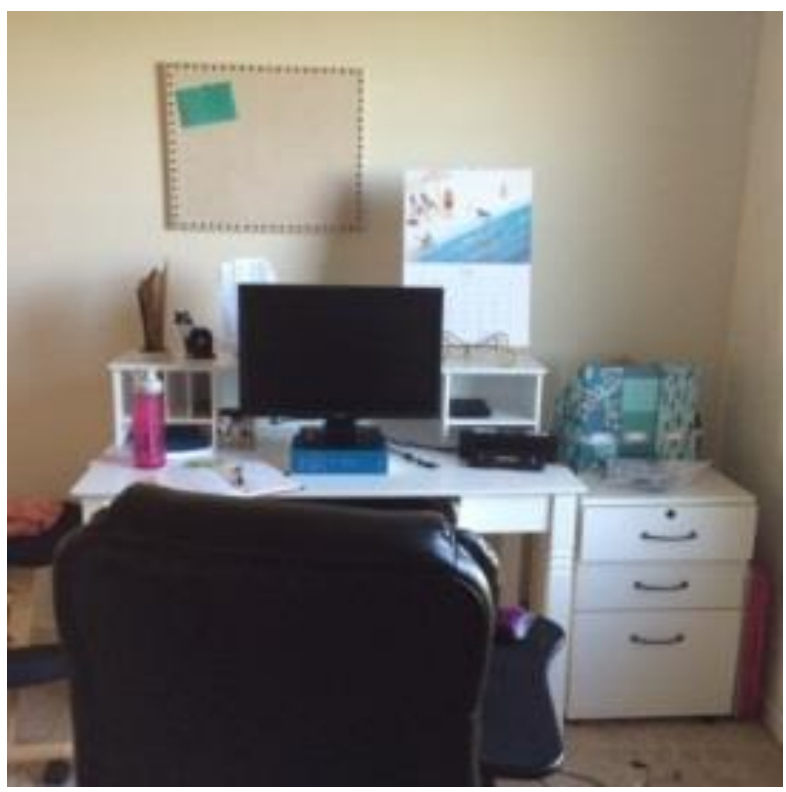

Figure 2. "This Is My Work Desk-Only Used for Work. Technology Here-Monitor, Laptop, Keyboard, Mouse, Chair, Also Have a Kneeling Chair" (Subject 10, Female, Age 30, Part Time)

A second theme, four participants mentioned was having their books present in their workspace. Figure 3 illustrates this theme.

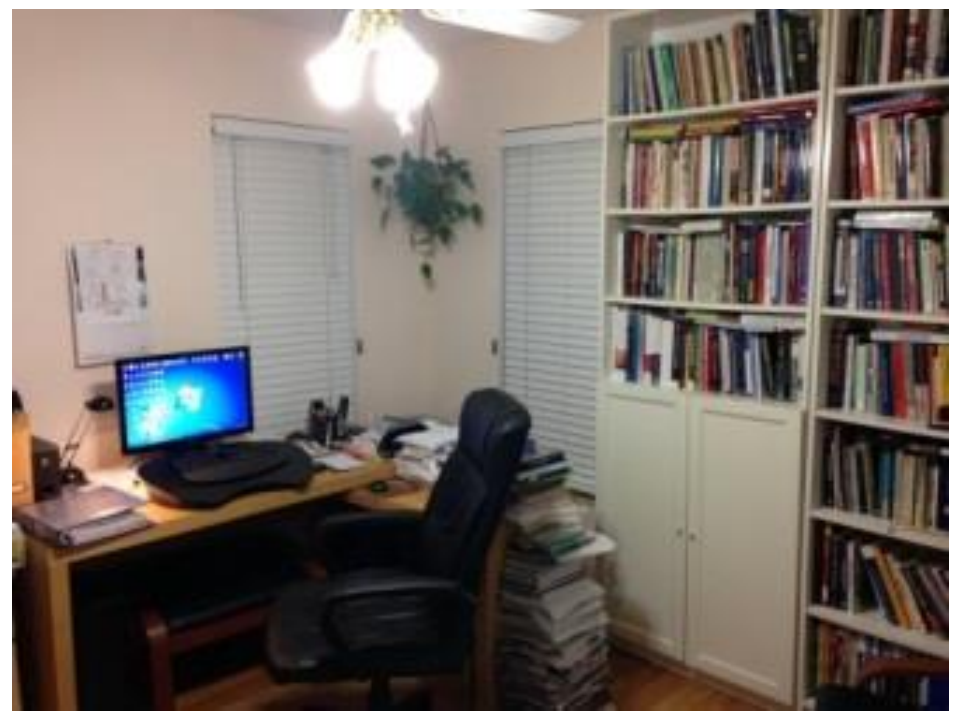

Figure 3. "This Is My Designated Area for Work, I Like Being Surrounded by Books" (Subject 18, Male, Age 49, Part Time) 
A third minor theme that was mentioned by three faculty members was that they chose the work location because of the view from their office. As shown in Figure 4, one participant submitted the view from her window.

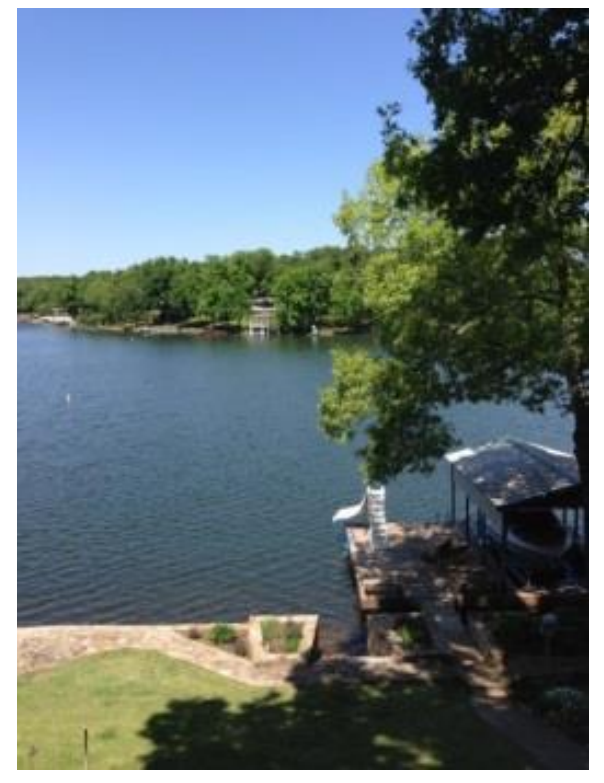

Figure 4. "Looking at the Lake, How Fortunate I Am to Live Here and Work From Home. It Is a Wonderful Place to Work" (Subject 2, Female, Age 54, Full Time)

Three discrepant cases are worthy of mention, in which faculty worked in areas of their home other than an office. These photos are provided in Figures 5-7. 


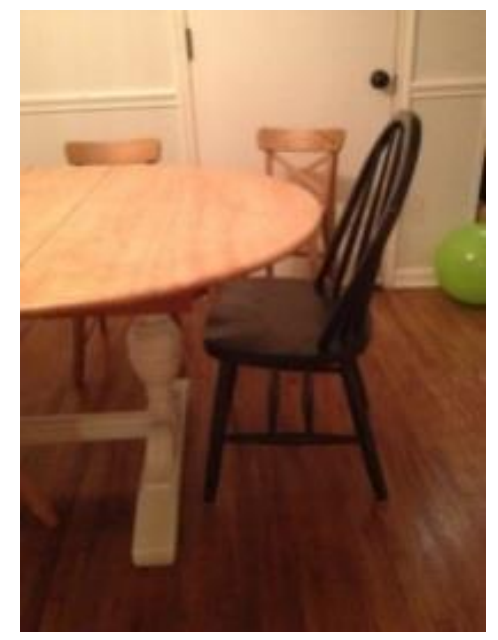

Figure 5. (I Work in My Kitchen.) "I Work Here During the Day-It Is a Place to Focus. It Is an Open Space, Makes Me More Alert, Has Bright Light. It Has an Outlet, I Like the Space" (Subject 13, Female, Age 36, Part Time)

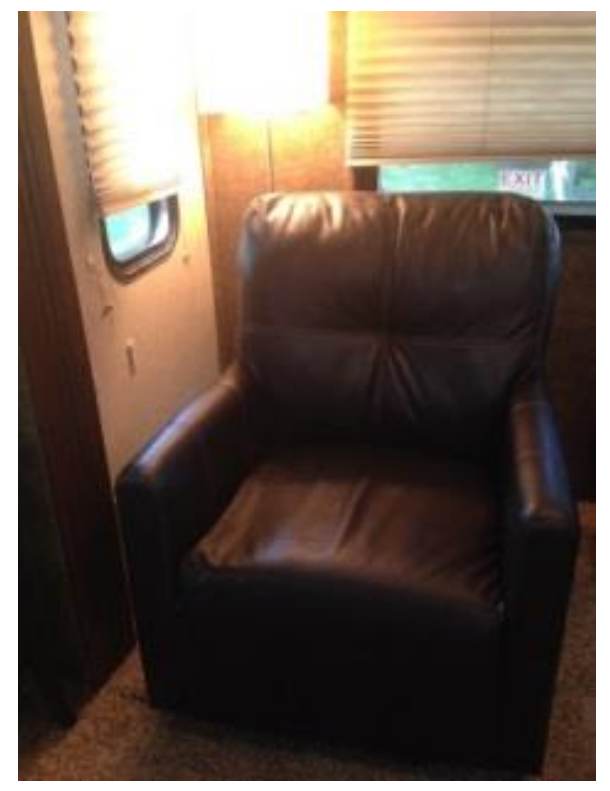

Figure 6. (Lives With Family in an RV, Photo of Chair in RV Living Room). "It Is Comfortable, Near Kids' Beds" (Subject 11, Female, Age 43, Part Time) 


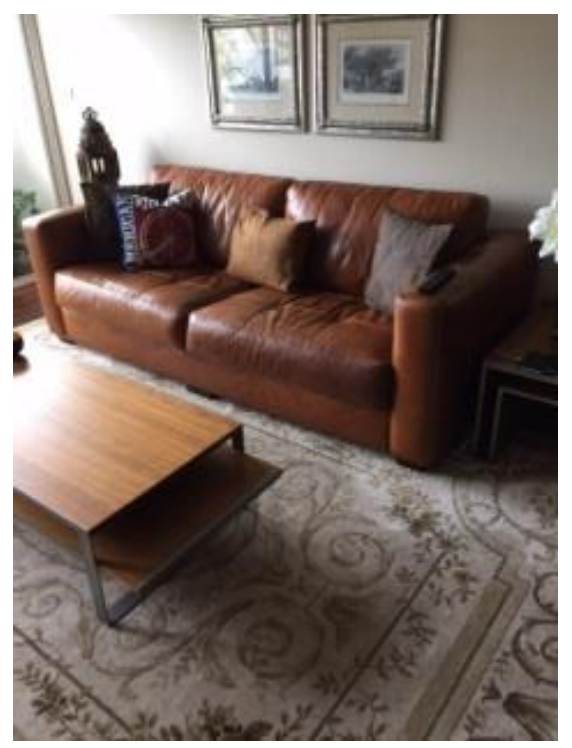

Figure 7. "I Work Mostly in the Living Room, but I Do Have a Desk in the Bedroom, Mostly Used to Pile Papers" (Subject 9, Male, Age 47, Full Time)

The use of photovoice in exploring online faculty member's home/ work area provided evidence that most faculty have clearly defined their work areas based on their use of technology. Of secondary concern in their work area is the surrounding space, such as having access to books and views from their window(s). Some individuals (these tended to be younger participants) do not rely on designated areas, but have tended to integrate their workspace in the living/ family areas.

\section{Discussion}

The present qualitative case study extended previous research and theory by exploring how online faculty members structure their home workplace. The majority of the participants consciously separated their home and workplace through either utilizing a separate room/area or maintaining a work schedule that separated work and home through the management of their time. However, the technology required for conducting their work (e.g., computer, printer, etc.) also appeared to play a strong role in the choice of maintaining a separate workspace; this was especially the case for fulltime faculty.

Most participants indicated that the ambiance of the home had not changed as a result of their online work. These findings support previous research in the area of telecommuting regarding worklife balance (Golden et al., 2006). It may be that those that are able to structure their home with clearly defined home and work areas are better able to maintain the ambiance of home and as a result develop a balance between work and home. Additional work in this area is needed.

Participants shared there were positive aspects of working at home, such as having the flexibility to set their own hours, being able to control work related interruptions, and having a reduction in their stress levels through not having a daily commute. However, they also shared aspects that negatively affected their ability to work, such as being lonely and missing the social aspect of the workplace. Faculty also felt the need to justify their work status with family and friends who encroached on their work time. 
The use of photovoice offered additional insights into how the participants perceived and thought about their workspace. The photos provided additional evidence of the separation the participants had established between home and work and the centrality of their work technology. Of secondary concern for a number of faculty members was the surroundings within their defined workspace; having their books available and a beautiful view from their window were mentioned.

The discrepant cases provided alternative counterpoints to the majority views, with a few individuals indicating no separation of work and home life; these individuals also tended to indicate never having time away from work. Younger faculty members were less likely to feel the need for a separate workspace and discussed either working within the family living space or moving with their laptop throughout the house. As the present study's participants tended to be older (with a mean age of 52.6 years), the use of on an office may be the result of a number of cohort or age-related factors. For example, older faculty may have been more likely to have worked previously in a brick-andmortar office environment, thus coming to equate work and office. Cognitive changes with aging may also make having a quiet, distraction less environment easier in which to work (Ilmarinen, 2001). Additional research is needed in this area.

The findings from the present study are consistent with Hyrkkänen et al.'s (2012) extension of Vischer's (2007) user-centered model of the virtual workplace. Participants tended to manage their physical, functional, and psychological comfort in performing their work related tasks through control of their physical space and time management. The present study extends the model with the integration of workspace with home needs, time management, and control of work surroundings (see Figures 8-10).

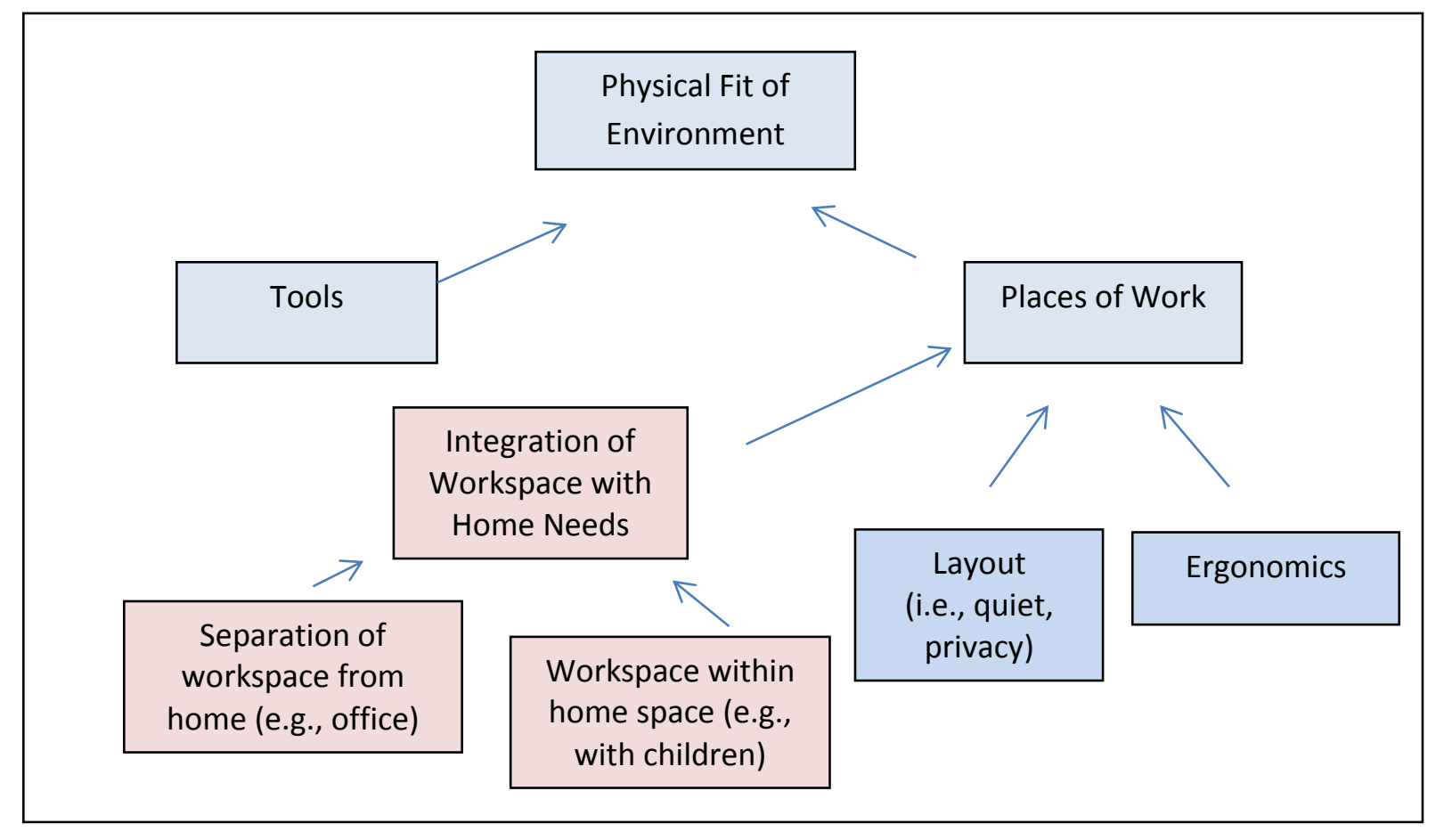

Figure 8. Model of Physical Fit of Work Environment (Blue From Hyrkkänen et al., 2012; Pink Indicates Additions to Model) 


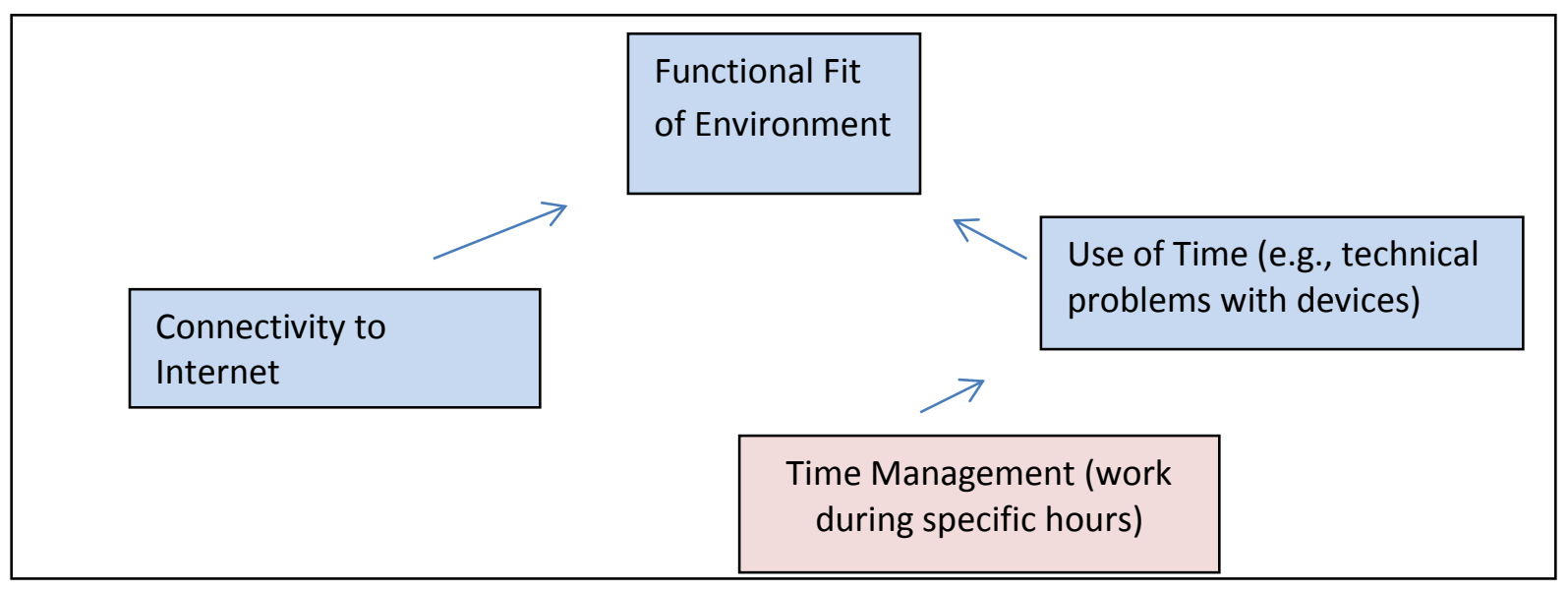

Figure 9. Model of Functional Fit of Work Environment (Blue From Hyrkkänen et al., 2012; Pink Indicates Additions to Model)

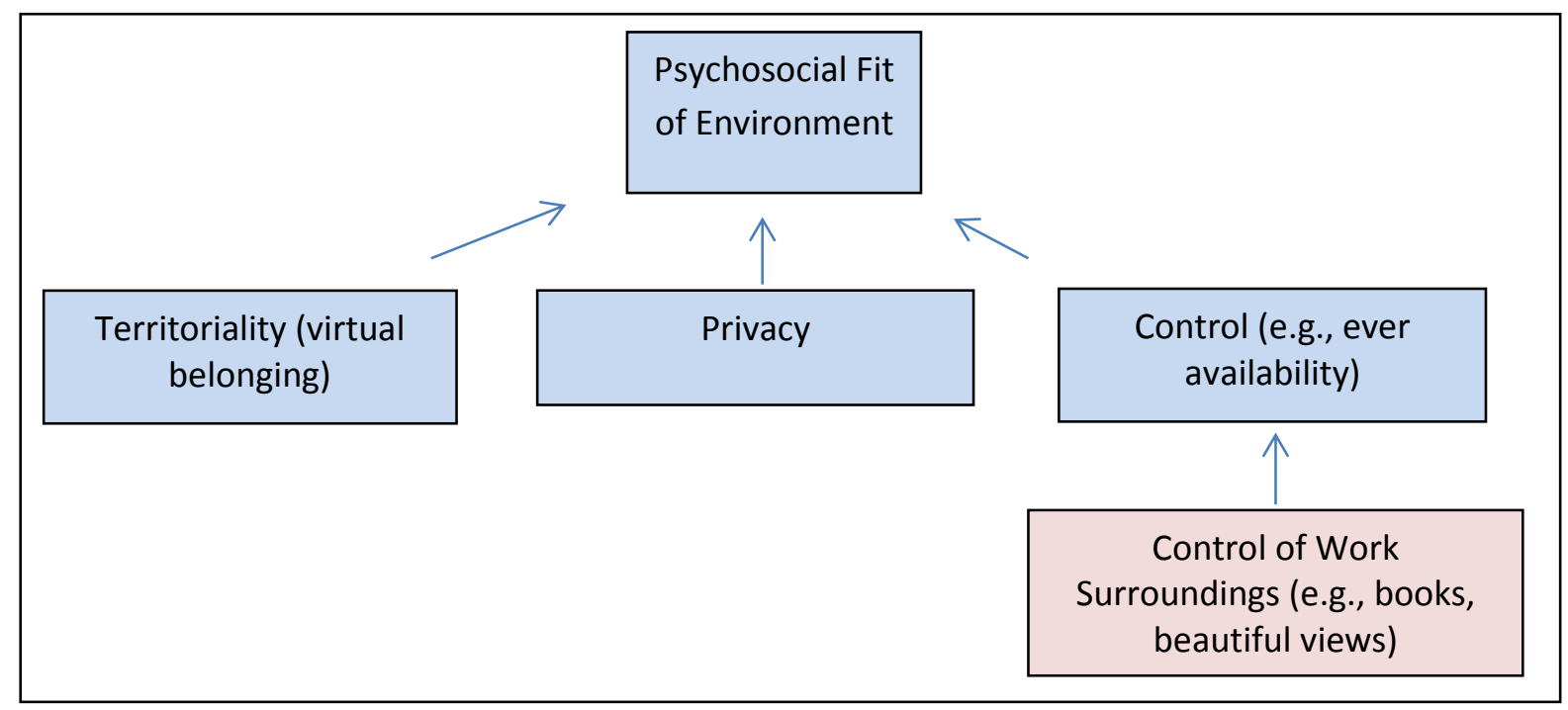

Figure 10. Model of Psychosocial Fit of Work Environment (Blue From Hyrkkänen et al., 2012; Pink Indicates Additions to Model)

\section{Limitations of the Study}

This study was conducted at a single large online university; faculty volunteered based upon an ad in the faculty newsletter. Because of this recruitment method, the sample tended to be older and was predominately female, Caucasian, and married. Presumably, only those individuals very interested in the topic chose to participate in the email and telephone interview. 


\section{Summary and Future Research}

The present study addressed a need in the current literature to understand how online workers (i.e., faculty) accommodate their workplace within their home and how the workplace affects their home environment. Given the results of the current study, virtual workers may find more work satisfaction by either separating their work area from the family home area or establishing separation by time. Understanding the needs of virtual workers provides employers with an opportunity to help new employees set up a controlled and secure work environment and better care for themselves, which may result in higher job satisfaction and productivity. Employers may be able to decrease the loneliness experienced by online faculty by establishing virtual communities where faculty can interact on a daily basis.

The results of the present qualitative case study provide a number of possible avenues of future research. Some examples include the differences in home working space for millennials versus older working adults. How do older home-based workers adjust their working environment to accommodate age related changes? Also of interest is how parents of small children work online at home, do they work while caring for their children or do they have other accommodations? As more knowledge accumulates on the online work/home interface, employers may wish to make suggestions and offer training for new employees on establishing and maintaining the work/home setting.

\section{References}

Allen, I. E., \& Seaman, J. (2016). Online report card: Tracking online education in the United States. Babson Park, MA: Babson Survey Research Group and Quahog Research Group, LLC.

Bureau of Labor Statistics. (2016, July 8). 24 percent of employed people did some or all of their work at home in 2015. Retrieved from http://www.bls.gov/opub/ted/2016/24-percent-of-employedpeople-did-some-or-all-of-their-work-at-home-in-2015.htm

Clark, C. M., Werth, L., \& Ahten, S. (2012). Cyber-bullying and incivility in the online learning environment, Part 1: Addressing faculty and student perceptions. Nurse Educator, 37, 150 156.

Eskey, M., \& Eskey, M. T. (2014). Cyberbullying in the online classroom: Faculty as the targets. Proceedings of the TCC Worldwide Online Conference 2014, 2014(1), 30-41.

Golden, T., Veiga, J., \& Simsek, Z. (2006) Telecommuting's differential impact on work-family conflict: Is there no place like home? The Journal of Applied Psychology, 91, 1340-1350.

Hill, J. E., Miller, B. C., Weiner, S. P., \& Colihan, J. (1998). Influences of the virtual office on aspects of work and work/life balance. Personnel Psychology, 51, 667-683.

Hyrkkänen, U., Kojo, I., \& Nenonen, S. (2012). The virtual reality of work-how to create a workplace that enhances well-being for a mobile employee. In C. S. Lanyi (Ed.), Virtual reality and environments (pp. 193-204). Retrieved from https://cdn.intechopen.com/pdfs-wm/36384.pdf

Igbaria, M., \& Guimaraes, T. (1999). Exploring differences in employee turnover intentions and its determinants among telecommuters and non-telecommuters. Journal of Management Information Systems, 16, 147-164.

Ilmarinen, J. E. (2001). Aging workers. Occupational Environmental Medicine, 58, 546-552. doi:10.1136/oem.58.8.546

Julien, H., Given, L., \& Opryshko, A. (2013). Photovoice: A promising method for studies of individuals' information practices. Library and Information Science Research, 35, 257-263. 
Kennedy, B., Mezu, K., Sawyer, H., Schenkel, S., Squillini, S., \& Underdahl, L. (2015). Stress management techniques used by faculty in the asynchronous learning environment. The Exchange: A Journal of the Academic Forum, 4, 79-85.

Kurland, N. B., \& Bailey, D. E. (1999). When workers are here, there, and everywhere: A discussion of the advantages and challenges of telework. Organizational Dynamics, 28, 53-68.

Madsen, S. R. (2003). The effects of home-based teleworking on work- family conflict. Human Resource Development Quarterly, 14, 35-58.

Murphy, M. J., Levant, R. F., Hall, J. E., \& Glueckauf, R. L. (2007). Distance education in professional training in psychology. Professional Psychology: Research and Practice, 38, 97 103. doi:10.1037/0735-7028.38.1.97

Nilles, J. M. (1994). Making telecommuting happen: A guide for telemanagers and telecommuters. New York, NY: Van Nostrand Reinhold.

Nuwer, R. (2016). No workplace like home. Scientific American Mind, 27, 38-43.

Oliver, C. (2009). Teaching at a distance: The online faculty work environment. Saarbrücken, Germany: VDM Verlag.

Pratt, J. H. (1999). 1999 Telework America National Telework Survey: Cost/benefits of teleworking to manage work/life responsibilities. Dallas, TX: International Telework Association and Council.

Rau, B. L., \& Hyland, M. M. (2002). Role conflict and flexible work arrangements: The effects on applicant attraction. Personnel Psychology, 55, 111-136.

Ross, L. M. (2016). The human side of virtual work: Managing, trust, isolation, and presence. New York, NY: Business Expert Press.

Stadtlander, L., Sickel, A., \& Giles, M. (2014, July 11). The online faculty work environment. Poster presented at the Walden University Summer Session, Washington, DC.

Stephens, G. K., \& Szajna, B. (1998). Perceptions and expectations: Why people choose a telecommuting work style. International Journal of Electronic Commerce, 3, 70-85.

Tustin, D. (2014). Telecommuting academics within an open distance education environment of South Africa: More content, productive, and healthy? International Review of Research in Open and Distance Learning, 15, 185-214.

Vischer, J. C. (2007). The effects of the physical environment on job performance: Towards a theoretical model of workspace stress. Stress and Health, 23, 175-184.

Vischer, J. C. (2008). Towards an environmental psychology of workspace: How people are affected by environments for work. Architectural Science Review, 51, 97-108.

\section{(Appendix follows)}




\section{Appendix}

\section{Email and Follow-Up Interview Questions}

\section{Email Interview Questions}

1. Tell me how you structure your home environment to be able to work online at home.

2. Do you feel that you separate your work environment from your home environment? If so, how do you do that? If you do not, then is this something you would like to do? Why or why not?

3. Do you structure your work environment and work day to reduce or control for interruptions (some possible examples, do not answer doorbell or phone, send children to a babysitter, etc.)? If you do so, please describe your methods and how well they work.

4. Do you feel that the ambiance or feeling about your home has changed for you or your family due to working at home? Describe the changes that you've seen.

5. Are there any other benefits/problems with working at home that you would like to share?

\section{Follow-Up Interview}

Looking at your photo of your workplace, describe in what ways this means a place to work for you. What particularly appeals to you about this area? Is there anything about the workspace that does not appeal to you? Why did you choose this as your workspace? Where is this area located in your home? Do you tend to work in just this area or work in different areas of your home?

The Journal of Educational Research and Practice provides a forum for studies and dialogue that allows readers to better develop social change in the field of education and learning. Journal content may focus on educational issues of all ages and in all settings. It also presents peer-reviewed commentaries, book reviews, interviews of prominent individuals, and additional content. The objectives: We publish research and related content that examines current relevant educational issues and processes aimed at presenting readers with knowledge and showing how that knowledge can be used to impact social change in educational or learning environments. Additional content provides an opportunity for scholarly and professional dialogue regarding that content's usefulness in expanding the body of scholarly knowledge and increasing readers' effectiveness as educators. The journal also focuses on facilitating the activities of both researcher-practitioners and practitioner-researchers, providing optimal opportunities for interdisciplinary and collaborative thought through blogging and other communications.

Walden University Publishing: http://www.publishing.waldenu.edu 